\title{
An Analysis of Fishing Selectivity for Northeast US Multispecies Bottom Trawlers
}

Andrew M. Scheld

Virginia Institute of Marine Science

John Walden

Follow this and additional works at: https://scholarworks.wm.edu/vimsarticles

Part of the Aquaculture and Fisheries Commons

\section{Recommended Citation}

Scheld, Andrew M. and Walden, John, "An Analysis of Fishing Selectivity for Northeast US Multispecies Bottom Trawlers" (2018). VIMS Articles. 1347.

https://scholarworks.wm.edu/vimsarticles/1347

This Article is brought to you for free and open access by the Virginia Institute of Marine Science at W\&M ScholarWorks. It has been accepted for inclusion in VIMS Articles by an authorized administrator of W\&M ScholarWorks. For more information, please contact scholarworks@wm.edu. 


\title{
An Analysis of Fishing Selectivity for Northeast US Multispecies Bottom Trawlers
}

Andrew M. Scheld, Virginia Institute of Marine Science, College of William \& Mary;

John Walden, Northeast Fisheries Science Center, NOAA Fisheries

\begin{abstract}
A B S T R A C T
Observed production sets in multispecies fisheries are affected by regulatory incentives influencing spatiotemporal fishing decisions. Rights-based output controls can promote selective fishing; however, this ability may be limited and insufficient in achieving full utilization of catch quotas. We measure fishing selectivity for bottom trawlers catching federally regulated groundfish in the Gulf of Maine and Georges Bank before and after the introduction of rights-based output controls. Directional distance functions are applied to tow-level catch data collected by fishery observers to construct a measure of selectivity equal to the difference between strong and weak output disposal efficient production frontiers. Quantile regressions are then used to estimate the change in median selectivity associated with the introduction of catch share management, controlling for spatial, temporal, and individual factors. A significant improvement in selectivity was found for tows in Georges Bank following the 2010 management change, though production is still largely characterized by imperfect selectivity.
\end{abstract}

Key words: Catch shares, directional distance function, fishing selectivity, multispecies fishery, production frontier, weak output disposability.

JEL Codes: D24, Q22.

\section{INTRODUCTION}

Bycatch and joint production in multispecies fisheries present perennial management problems and complicate the application of rights-based single species output controls (Copes 1986; Squires et al. 1998; Grafton et al. 2006). In catch share and quota-regulated multispecies fisheries, technological interactions between separately managed species can incentivize discarding as well as result in over- or under-utilization of allowable catch allocations (Turner 1997; Singh and Weninger 2009; Kuriyama et al. 2016). Balance between catch and quota may be achieved with use of institutional or regulatory mechanisms intended to add flexibility to joint production possibilities by, for example, allowing trade of quota between different quota holders, quota rollover across seasons, or quota conversions between different species (Sanchirico et al. 2006). When such provisions are absent, or in cases of widely disparate allowable catch limits, increased utilization of quota allocations requires selective fishing by individual fishers.

Andrew M. Scheld is an assistant professor, Department of Fisheries Science, Virginia Institute of Marine Science, College of William \& Mary, PO Box 1346, Gloucester Point, VA 23062 USA (email: scheld@vims.edu). John Walden is an economist, Northeast Fisheries Science Center, NOAA Fisheries, 166 Water St., MB 19, Woods Hole, MA 02543 USA (email: john.walden@noaa.gov).

The authors thank participants at the 2017 North American Association of Fisheries Economists biennial meeting and two anonymous reviewers for helpful comments. This article is Contribution No. 3765 of the Virginia Institute of Marine Science, College of William \& Mary.

Received January 11, 2018; Accepted July 13, 2018; Published online August 13, 2018. http://dx.doi.org/10.1086/699712

Marine Resource Economics, volume 33, number 4. () 2018 MRE Foundation, Inc. All rights reserved. 0738-1360/2018/3304-0002\$10.00 
Empirical studies have frequently found multispecies joint production technologies to be nonor imperfectly selective, leading many to question the feasibility of multispecies rights-based output controls (Squires 1987; Squires and Kirkley 1991; Pascoe, Koundouri, and Bjørndal 2007; Pascoe, Punt, and Dichmont 2010). Analyses that have followed transitions to multispecies catch share or quota programs have, conversely, shown improvements in compositional control postimplementation (Branch and Hilborn 2008; Abbott, Haynie, and Reimer 2015). Enhanced species targeting or avoidance can frequently be attributed to spatial or temporal changes in gear deployment and operation. Examples include: fishing more frequently in areas where catch compositions align with allocation limits (Branch and Hilborn 2008; Abbott, Haynie, and Reimer 2015), abrupt movements following encounters with low quota or bycatch species (Abbot, Haynie, and Reimer 2015), and modifying the time of day in gear deployment (Abbot, Haynie, and Reimer 2015). Empirically revealed production sets are thus not policy invariant but depend on behavioral incentives that influence where, when, and how fishing occurs (Reimer, Abbott, and Wilen 2017; Reimer, Abbott, and Haynie 2017).

In this article, we evaluate empirically revealed multispecies production frontiers prior to and following a large-scale expansion of rights-based output controls in the Northeast multispecies fishery (i.e., groundfish), introduced in 2010 through Amendment 16 (A16) to their fishery management plan (FMP). ${ }^{1}$ Our analysis focuses on joint production of Atlantic cod (Gadus morhua) and haddock (Melanogrammus aeglefinus), two of thirteen demersal species managed under the FMP. Both species are high-valued targets, regularly receiving upwards of $\$ 2 / \mathrm{lb}$. ex-vessel, and are frequently caught together. Each species faces different regulatory and management pressures, however. Cod populations are thought to be well below historic levels. Recent assessments have concluded that cod stocks are overfished and that overfishing is occurring (NEFSC 2015). Conversely, haddock populations have been found to be healthy and highly abundant. As a result, fishery managers would like to increase harvests and landings of haddock while simultaneously reducing (or maintaining) those of cod. It was thought that the introduction of rights-based output controls would incentivize selective fishing and lead to healthier, more profitable fishery resources (NEFMC 2009).

Under A16, strict annual catch limits (ACLs) for the fleet were established for all stocks managed by the FMP, along with accountability measures if an ACL was violated. Before 2010, most stocks were managed using target catches, achieved through vessel trip limits and a variety of effort controls. A16 led to the authorization of 17 "sectors" - groups of vessels that voluntarily enter a contract and agree to jointly manage collective annual allocations. Each sector was allocated tradable (between sectors) quotas based on members' historical landings for fourteen stocks of nine groundfish species: Atlantic cod, haddock, pollock (Pollachius virens), Acadian redfish (Sebastes fasciatus), yellowtail flounder (Limanda ferruginea), American plaice (Hippoglossoides platessoides), witch flounder (Glyptocephalus cynoglossus), winter flounder (Pseudopleuronectes americanus), and white hake (Urophycis tenuis). Only stocks with harvest moratoriums and Atlantic halibut (Hippoglossus hippoglossus), which has a strict one fish possession limit, were ex-

\footnotetext{
1. In 2004, Amendment 13 to the FMP allowed a small group of vessels using hook and line gear and concentrated in a single geographic area (Cape Cod) to jointly manage a collective allocation for a single stock-Georges Bank cod. The group was responsible for ensuring that their total catch did not exceed their allocation; however, trips landing other FMP species were still subject to prior restrictions. This arrangement was extended in 2006 through Framework Adjustment 42 to an additional group of vessels in the same geographic area that also used fixed gear (i.e., hook and line or gillnets). The majority of the fleet, including all bottom trawl vessels, fished under effort controls (e.g., days-at-sea) until 2010.
} 
cluded from the new collective quota program. Vessels that did not join a sector were allowed to fish under a separate effort control system. Most vessels elected to join sectors however, and in 2010, over $98 \%$ of allowable catch was allocated in the form of collective group quotas (Murphy et al. 2011; Lee and Thunberg 2013).

To explore the relationship between rights-based output controls and multispecies production sets, we first construct a measure of fishing selectivity as the difference between efficient production frontiers satisfying conditions of strong and weak output disposal. A non-zero frontier separation indicates weak output disposability and imperfect multispecies fishing selectivity. We then use quantile regressions to evaluate correspondence between changes in selectivity and the introduction of the fleet-wide multispecies catch share program. Our findings indicate that fishing selectivity improved subsequent to the introduction of rights-based output controls for observed bottom trawls in Georges Bank, suggesting that institutional incentives may have promoted greater compositional control. Conclusions add further support to the idea that revealed production possibilities are frequently constrained and confounded by regulatory incentives (Reimer, Abbott, and Wilen 2017; Reimer, Abbott, and Haynie 2017) while also suggesting that a limited ability to fish selectively may ultimately restrict complete utilization of catch quotas in the US Northeast multispecies fishery.

\section{CONCEPTUAL FRAMEWORK}

A joint production output frontier is the boundary of a producible set indicating combinations of maximum output producible with a fixed input level (figure 1). Convex output frontiers may exhibit either strong or weak output disposability. Weak output disposability means that in or-

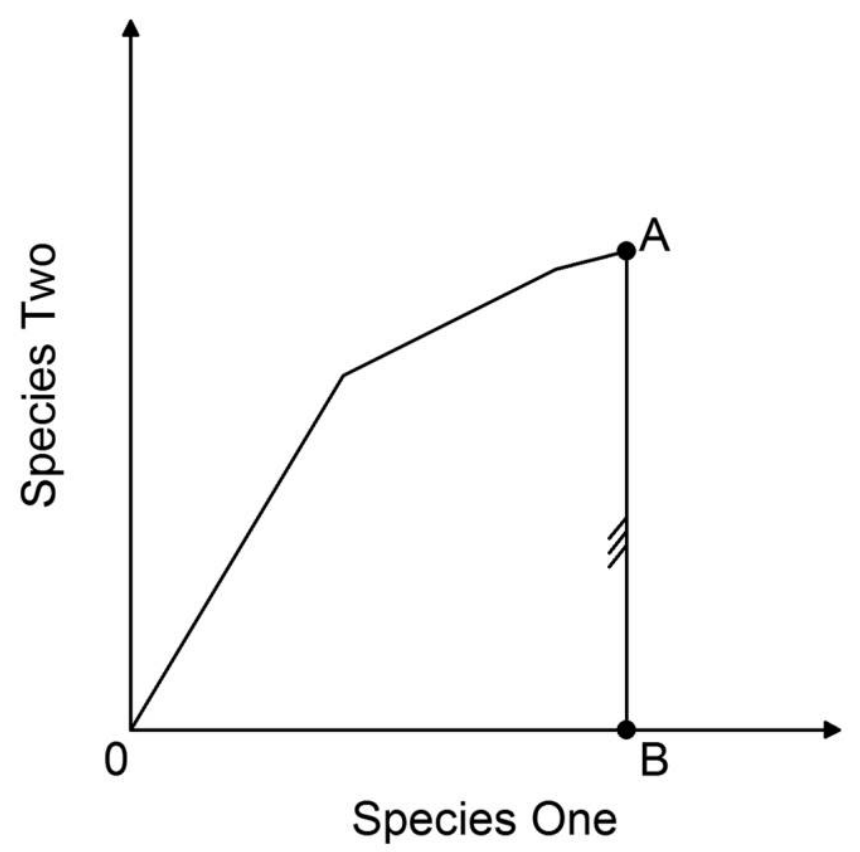

Figure 1. Multispecies Production Frontier

Note: Frontier exhibits weak (OA) and strong (AB) output disposability. 
der to reduce one output, all other jointly produced outputs will simultaneously need to be reduced, or inputs will need to be increased to maintain the output levels for the jointly produced outputs (Shephard 1970; Färe, Grosskopf, and Lovell 1994). In a multispecies fishery, weak output disposability implies catch reductions of a single species require reductions in catch of jointly produced species or increased inputs, such as fuel to reach areas with lower concentrations of the avoided stock (Turner 1997; Singh and Weninger 2009). Strong output disposal corresponds to negative or zero marginal rates of product transformation, and, in a multispecies fishery, suggests complete and perfect compositional control, as decreases in output of one species could be accomplished without corresponding decreases in joint outputs.

An output-oriented reference technology can be defined as:

$$
P(\boldsymbol{x})=\{\boldsymbol{y}: \boldsymbol{x} \text { can produce } \boldsymbol{y}\}
$$

where $\boldsymbol{x}=\left(x_{1}, \ldots, x_{N}\right) \in \mathbb{R}_{+}^{N}$ is a vector of $N$ inputs, $\boldsymbol{y}=\left(y_{1}, \ldots, y_{M}\right) \in \mathbb{R}_{+}^{M}$ is a vector of $M$ outputs, and $P(\boldsymbol{x})$ is the set of all feasible output combinations producible given an input vector $\boldsymbol{x}$.

Two contrasting multispecies output sets will be considered, one characterized by strong output disposability, $P_{s}(\boldsymbol{x})$, and another that satisfies conditions of weak output disposal, $P_{w}(\boldsymbol{x})$. The following restrictions, in addition to (1), define each output set:

$$
\begin{gathered}
y \in P_{s}(\boldsymbol{x}), \boldsymbol{y}^{\prime} \leq \boldsymbol{y} \text { imply } \boldsymbol{y}^{\prime} \in P_{s}(\boldsymbol{x}), \\
\boldsymbol{y} \in P_{w}(\boldsymbol{x}), 0 \leq \theta \leq 1 \text { imply } \theta \boldsymbol{y} \in P_{w}(\boldsymbol{x}) .
\end{gathered}
$$

Condition (2) indicates that when $\boldsymbol{y}$ is within the set $P_{s}(\boldsymbol{x})$ producing any amount less than or equal to $y$ is also feasible. For a multispecies production technology, this implies output of any species can be reduced without additional inputs or reductions in jointly produced outputs; i.e., outputs are strongly disposable. Weak output disposability is introduced through condition (3) by allowing only proportionate output contractions. The technological restrictions on outputs in (3) are similar to those used when specifying environmental production technologies (see Färe, Grosskopf, and Pasurka 2007). However, in this instance, it is not necessary to consider nulljointness as it is possible to have zero and non-zero elements in $\boldsymbol{y}^{2}$ Note that $P_{s}(\boldsymbol{x})$ and $P_{w}(\boldsymbol{x})$ are also assumed to be compact and allow for inactivity, which are common restrictions placed on output sets (see Shephard 1970 and Färe, Grosskopf, and Lovell 1994 for additional details on production sets characterized by strong and weak output disposability).

By construction, $P_{w}(\boldsymbol{x}) \subseteq P_{s}(\boldsymbol{x})$ as all outputs satisfying (3) also satisfy (2). In deriving both $P_{s}(\boldsymbol{x})$ and $P_{w}(\boldsymbol{x})$ for a particular set of inputs and outputs, we enable measurement of frontier separation. Production points contained within $P_{s}(\boldsymbol{x})$ but not $P_{w}(\boldsymbol{x})$; i.e., the set $P_{s}(\boldsymbol{x}) \backslash P_{w}(\boldsymbol{x})$, are infeasible output combinations with respect to the weakly disposable production set, yet feasible under perfect compositional control. A large separation between strong and weak output disposal pro-

2. Null-jointness is typically invoked when specifying production technologies that generate undesirable joint outputs (pollution). This condition states that zero production of the undesirable output requires zero production of the desirable output (Färe and Grosskopf 2004). Such a condition is not necessary in multispecies fisheries, where all outputs may be desirable. 
duction frontiers, implying many output combinations contained within the set $P_{s}(\boldsymbol{x}) \backslash P_{w}(\boldsymbol{x})$, suggests limited compositional control and significant costs associated with output reductions of individual species. In what follows, we will, at times, describe production sets characterized by weak (strong) output disposal as exhibiting weak (strong) selectivity.

\section{DATA}

Data on production inputs and outputs was obtained from the Northeast Fisheries Science Center's Fisheries Sampling Branch. Tow-level catches (kept and discarded lbs.) of species and species aggregates were used as production outputs. Fishing inputs considered fixed (vessel gross tons, horsepower, and length) and variable factors (number of crew, haul duration). ${ }^{3}$ All data were collected by fisheries observers through the Northeast Fisheries Observer Program (NEFOP). Observer coverage varies year-to-year and is based on achieving a 30\% coefficient of variation on estimates of fishery discards for federally managed species and sea turtles, following the Standardized Bycatch Reporting Methodology (NEFMC, MAFMC, and NOAA 2007). The program operates across several dozen fleets throughout New England and the Mid-Atlantic and is chiefly focused on estimating total annual discards for 15 species or species groups. Typically, between 5 and $10 \%$ of Northeast multispecies groundfish trips are observed each year. Observers are assigned to specific trips based on a stratified random design, such that an unbiased sample of observed discards by the groundfish fleet is attained. ${ }^{4}$ Prior to 2010, dockside intercepts were used to select trips. The introduction of A16 required dynamic, random sample stratification, leading to the development of a pre-trip notification system where vessels are notified of observer coverage 48 hours prior to departure (Palmer et al. 2013).

We considered observed tows by otter trawlers fishing in the Gulf of Maine (figure 2, statistical areas 464, 465, 511, 512, 513, 514, and 515) and Georges Bank (figure 2, statistical areas 521, $522,525,526,561$, and 562) from fishing year (FY) 2007 through FY 2014. ${ }^{5}$ Otter trawlers tow a net off their stern on the ocean floor that uses otter boards to force the net open while pulled and are the dominant class of trawl vessels in the fleet. Observations from the statistical areas included represented $86 \%$ of NEFOP tows taken by otter trawlers. The remaining $14 \%$ of tows occurred primarily in Southern New England, where Northeast multispecies groundfish is caught less frequently and in smaller amounts ( $<3 \%$ of catch, on average). To ensure adequate sample sizes when constructing production frontiers, observed tows were stratified by statistical area and month in each FY and all area-month strata with fewer than 10 observations were dropped from analysis. The final dataset contained 40,692 observed tows by 408 vessels across eight FYs.

Catch amounts and compositions differed between the two fishing regions. Average total catches (kept and discarded lbs., all species) in the Gulf of Maine and Georges Bank were 1,811 and 2,525 lbs. per tow, respectively. In the Gulf of Maine, pollock, Acadian redfish, and white hake typically made up $33 \%$ of catch per tow. However, these species accounted for only $6 \%$ of catch, on average, in Georges Bank. Species not managed under the multispecies FMP made up two-thirds of catch in Georges Bank, compared with less than half in the Gulf of Maine. Cod catch compositions were roughly equal between the two regions, on average (7-8\% per tow); however, haddock

3. Number of crew might be considered semi-fixed, as it is fixed for all tows within a trip but can vary across trips.

4. Stratification is by gear, location/target stock, and, as of 2010, sector. Stratification by sector is necessary as estimated sector discards are counted against allocations.

5. A fishing year begins on May $1^{\text {st }}$. 


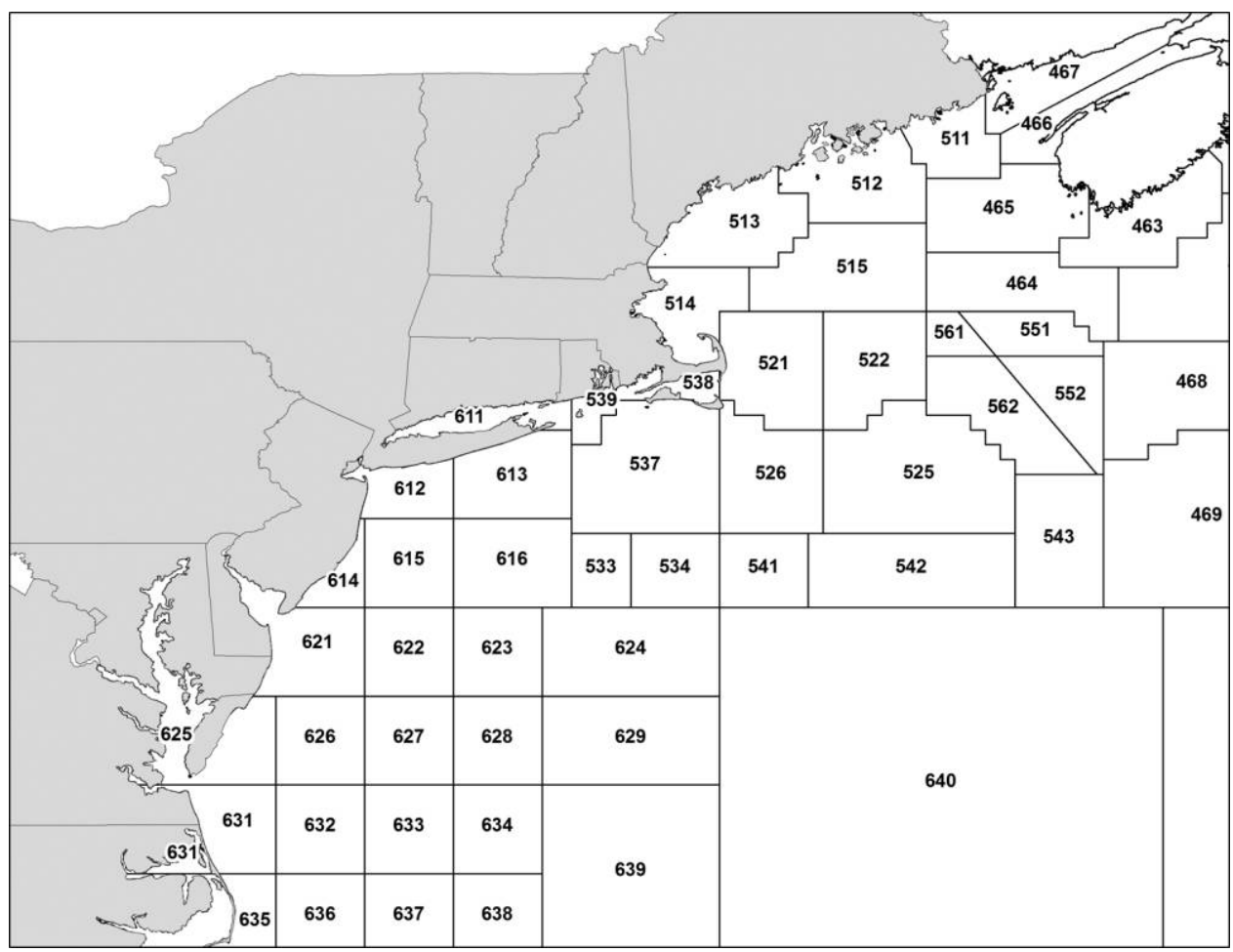

Figure 2. Statistical Areas for the Greater Atlantic Region

was caught less frequently and in smaller amounts in the Gulf of Maine (table 1). Neither cod nor haddock were ever caught without some amount of other species. Sector sub-ACLs allocated to the catch share fleet also differed substantially across species and fishing regions. Catch limits for cod were similar in the Gulf of Maine and Georges Bank, though the ACL for Georges Bank haddock was considerably larger than that for Gulf of Maine haddock and both cod ACLs (table 1).

Differences in fishing inputs between the two regions were less dramatic. On average, vessels operating on Georges Bank tended to be slightly larger and had more crew compared to those

Table 1. Summary Statistics for Cod and Haddock Fisheries

\begin{tabular}{lccc}
\hline Stock & ${\text { Catch } \text { Tow }^{-1}}^{-}$ & $>(\%)$ & Sector sub-ACL \\
\hline Cod GOM & $169(516)$ & 65 & $2,858(1,910)$ \\
Cod GB & $147(338)$ & 72 & $3,292(1,352)$ \\
Haddock GOM & $30(214)$ & 52 & $567(258)$ \\
Haddock GB & $264(864)$ & 62 & $36,531(10,058)$ \\
\hline
\end{tabular}

Note: Mean catch per tow (kept and discarded lbs.), percentage of tows with non-zero catch, and average sector sub-ACLs 2010-2014 in metric tons for cod and haddock caught in the Gulf of Maine (GOM) and Georges Bank (GB) are presented. Standard deviations are given in parentheses. 
Table 2. Summary Statistics for Fishing Inputs

\begin{tabular}{lcc}
\hline Input & Mean GOM & Mean GB \\
\hline Length (ft.) & $65.61(13.99)$ & $76.01(6.65)$ \\
Gross Tons & $102.63(56.71)$ & $142.60(32.41)$ \\
Horsepower & $541.92(229.18)$ & $645.80(211.54)$ \\
Crew & $3.24(1.10)$ & $4.07(0.64)$ \\
Haul Duration (hrs.) & $4.16(2.37)$ & $3.54(1.44)$ \\
\hline
\end{tabular}

Note: Mean values of fishing inputs for observed tows in the Gulf of Maine (GOM) and Georges Bank (GB). Standard deviations are given in parentheses.

fishing in the Gulf of Maine. The duration of tows tended to be slightly longer in the Gulf of Maine, however (table 2).

\section{METHODS}

The separation between output frontiers characterized by strong and weak output disposability was used as a measure of compositional control (see Färe, Grosskopf, and Pasurka 2007; Scheld and Anderson 2016). Directional distance functions (Chambers, Chung, and Färe 1996; Chung, Färe, and Grosskopf 1997) were applied to first identify output distances to each frontier, before constructing a measure of frontier separation. Directional distance functions were specified as:

$$
\begin{gathered}
\vec{D}_{s}\left(\boldsymbol{x}, \boldsymbol{y}, \boldsymbol{g}_{y}\right)=\max \left\{\beta: \boldsymbol{y}+\beta \boldsymbol{g}_{y} \in P_{s}(\boldsymbol{x})\right\}, \\
\vec{D}_{w}\left(\boldsymbol{x}, \boldsymbol{y}, \boldsymbol{g}_{y}\right)=\max \left\{\beta: \boldsymbol{y}+\beta \boldsymbol{g}_{y} \in P_{w}(\boldsymbol{x})\right\} .
\end{gathered}
$$

In (4) and (5), $\boldsymbol{x}$ and $\boldsymbol{y}$ are vectors of multispecies fishing inputs and outputs; $P_{s}(\boldsymbol{x})$ and $P_{w}(\boldsymbol{x})$ are multispecies output sets adhering to conditions of strong and weak output disposability, respectively; $\boldsymbol{g}_{y} \in \mathbb{R}_{+}^{M}$ is a vector defining the distance function's direction of output expansion; and $\beta$ is a scalar factor that measures how far $y$ could expand, in the direction $\boldsymbol{g}_{\boldsymbol{y}}$, while still remaining producible given the restrictions of a particular output set.

Differencing (4) and (5) yields a measure of frontier separation:

$$
\phi\left(\boldsymbol{x}, \boldsymbol{y}, \boldsymbol{g}_{y}\right)=\vec{D}_{s}\left(\boldsymbol{x}, \boldsymbol{y}, \boldsymbol{g}_{y}\right)-\vec{D}_{w}\left(\boldsymbol{x}, \boldsymbol{y}, \boldsymbol{g}_{y}\right) .
$$

The measure constructed in (6) identifies additional output that could be feasibly produced if outputs were strongly disposable. As this difference approaches zero, compositional control in the observed multispecies production technology is increasingly less costly. A value of zero indicates that, for inputs $\boldsymbol{x}$, outputs $\boldsymbol{y}$, and output direction $\boldsymbol{g}_{\boldsymbol{y}}$, the revealed production set exhibits strong output disposability, or strong selectivity. This measure is an extension of a metric originally developed to investigate the effect of regulatory controls on production of desirable outputs by polluting industries, noted as the opportunity costs of environmental regulations restricting free pollution disposal (Färe, Grosskopf, and Pasurka 2007). In a multispecies context, this measure might be thought of as the additional catch or production possible given perfect fishing selectivity (Scheld and Anderson 2016). 
Empirical measurement of (6) was performed using data envelopment analysis (Farrell 1957; Charnes, Cooper, and Rhodes 1978), which required solving the following linear programming routines:

$$
\begin{aligned}
& \vec{D}_{s}\left(\boldsymbol{x}^{k^{\prime}}, \boldsymbol{y}^{k^{\prime}}, \boldsymbol{g}_{y}\right)=\max _{\beta, \lambda} \beta \\
& \text { s.t. } \sum_{k=1}^{K} \lambda_{k} y_{m, k} \geq y_{m, k^{\prime}}+\beta g_{y_{m}}, \quad m=1, \ldots, M \\
& \sum_{k=1}^{K} \lambda_{k} x_{n, k} \leq x_{n, k^{\prime}}, \quad n=1, \ldots, N \\
& \lambda_{k} \geq 0, \quad k=1, \ldots, K ; \\
& \vec{D}_{w}\left(\boldsymbol{x}^{k^{\prime}}, \boldsymbol{y}^{k^{\prime}}, \boldsymbol{g}_{y}\right) \max _{\beta, \lambda} \beta \\
& \text { s.t. } \quad \sum_{k=1}^{K} \lambda_{k} y_{m, k}=y_{m, k^{\prime}}+\beta g_{y_{m}}, m=1, \ldots, M \\
& \\
& \sum_{k=1}^{K} \lambda_{k} x_{n, k} \leq x_{n, k^{\prime}}, \quad n=1, \ldots, N \\
& \lambda_{k} \geq 0, \quad k=1, \ldots, K .
\end{aligned}
$$

In (7) and (8), output distances to strong and weak output disposal efficient frontiers are found for observation $k^{\prime}$ in the direction $\boldsymbol{g}_{\boldsymbol{y}}$. Intensity variables, $\lambda_{k}$, are weights used to construct the efficient frontier for each respective technology. There were no constraints imposed on the summation of $\lambda_{k}$, implying constant returns to scale. ${ }^{6}$

Problems (7) and (8) differ only in their constraints associated with outputs $y$. In (7), feasible production includes any output level that is less than or equal to a convex combination of points along the frontier - the condition of strong output disposability. Feasible production in (8) instead requires equality between outputs at observation $k^{\prime}$ (expanded in direction $\boldsymbol{g}_{\boldsymbol{y}}$ ) and the production frontier. To illustrate the difference, consider two production observations using identical input levels but producing differing amounts of outputs. Observation one has an output vector of $\boldsymbol{y}^{\boldsymbol{1}}=(100,50)$, while observation two has output levels shown by the vector $\boldsymbol{y}^{\mathbf{2}}=$ $(75,25)$. Evaluating programming problems (7) and (8) for the second observation $\left(y^{2}\right)$ using a directional vector, $\boldsymbol{g}_{\boldsymbol{y}}$, that expands additively in the first output direction (i.e., $\boldsymbol{g}_{\boldsymbol{y}}=(1,0)$ ) yields a value of 25 in (7) and 0 in (8). The former value results as positive weight is placed on the first observation $\left(y^{\boldsymbol{I}}\right)$, which meets output constraints $(100 \geq 75+\beta$ and $50 \geq 25)$ and defines the efficient frontier under conditions of strong output disposal. The value of 0 found for (8), meanwhile, arises as positive weight is placed on the second observation $\left(y^{2}\right)$ as a result of equality constraints for weakly disposable outputs. In this example, perfect compositional control would en-

6. The assumption of constant returns to scale was utilized in the original specification by Färe, Grosskopf, and Pasurka (2007) and is reasonable here given that we are analyzing tow-level catches by area-month-FY strata for vessels using the same gear. Models that allowed for variable returns to scale were tested and yielded similar results. 
able the second observation $\left(y^{2}\right)$ to produce at least 25 more units of the first output — as much as are produced in the first observation $\left(y^{\boldsymbol{I}}\right)$. $^{7}$

Observer data collected through the NEFOP was used in constructing empirical multispecies production frontiers. Five production inputs were considered: haul duration, number of crew, vessel length, vessel gross tons, and horsepower. Haul duration is the only input that might vary across different tows on a given trip, while the number of crew could vary across trips for a given vessel. Catches (kept and discarded lbs.) of five species, or groups of species, were considered as production outputs: cod, haddock, other roundfish managed within the multispecies FMP, flatfish managed within the multispecies FMP, and all other species managed outside the multispecies FMP. Within each FY, strong and weak selectivity production frontiers were constructed considering observations of inputs and outputs by area-month strata, leading to 1,248 possible frontiers (13 statistical areas $\times 12$ months $\times 8 \mathrm{FYs}){ }^{8}$

Two specifications of the directional vector were used. First, $\phi$ values were found by additively expanding haddock (i.e., $\boldsymbol{g}_{\boldsymbol{y}}=(0,1,0,0,0)$, where haddock is the second element of $\boldsymbol{y}$ ). This specification returned a value that corresponded to the additional haddock catch possible under efficient production and free disposal of non-haddock, ceteris paribus (figure 3). ${ }^{9}$ The second specification of $\boldsymbol{g}_{\boldsymbol{y}}$ simultaneously expanded haddock, roundfish, flatfish, and the aggregate of species managed outside the multispecies FMP, holding cod catch fixed (i.e., $\boldsymbol{g}_{y}=(0,1,1,1,1)$, where cod is the first element of $\boldsymbol{y}$ ). Under this specification, resulting values of $\phi$ captured the potential increase in catch for each of the four non-cod outputs given efficient production and free cod disposal, ceteris paribus. While the former specification of the directional vector corresponded to the additional haddock catch possible if haddock could be perfectly targeted, the latter captured multi-output impacts of imperfect cod avoidance.

Median frontier separation was used as a measure of central tendency as the distributions for bounded statistics are frequently skewed. Medians by FY for the Gulf of Maine and Georges Bank were bootstrapped by resampling with replacement from the set of $\phi$ values - where each $\phi$ value corresponded to the difference between strong and weak output disposal efficient frontiers for an individual tow. ${ }^{10}$ In each bootstrap iteration, a new sample of $\phi$ values, equal in size to the original sample, was drawn and the median was stored. This process was repeated 10,000 times for each fishing region in each FY. A median was considered statistically different from zero when less than $5 \%$ of the bootstrap distribution was equal to zero, corresponding to a $95 \%$ confidence level. ${ }^{11}$ Mood's median tests were used to detect changes in median values for the Gulf of Maine and Georges

7. In this simple example, production inefficiency (under strong output disposal) and the costs imposed due to limited compositional control are equivalent. This would not necessarily be the case in scenarios involving more than two observations, and is not true whenever an observation is interior to the weak output disposal efficient frontier.

8. Though fine-scale fishing location data is collected through the observer program, some level of spatial aggregation was necessary to construct empirical production frontiers. Aggregating by statistical area kept our analyses aligned with management and stock delineations. Nevertheless, a tradeoff exists between spatial and temporal disaggregation, which reduces the likelihood of confounding processes, and aggregation across fishing locations and time, which enables construction of densely populated production frontiers.

9. Free disposal of non-haddock implies perfect avoidance of all non-haddock outputs or, analogously, perfect haddock targeting.

10. A median value taken from observations associated with production frontiers constructed across multiple strata is affected by both differences in production possibilities among different strata, as well as the number of observations in each strata and their distribution in output space (e.g., a low level of median selectivity could indicate either uniformly low selectivity across strata or a disproportionate number of observations from a low selectivity strata).

11. This would imply that in $95 \%$ or more of bootstrapped samples at least half of $\phi$ were greater than zero. 


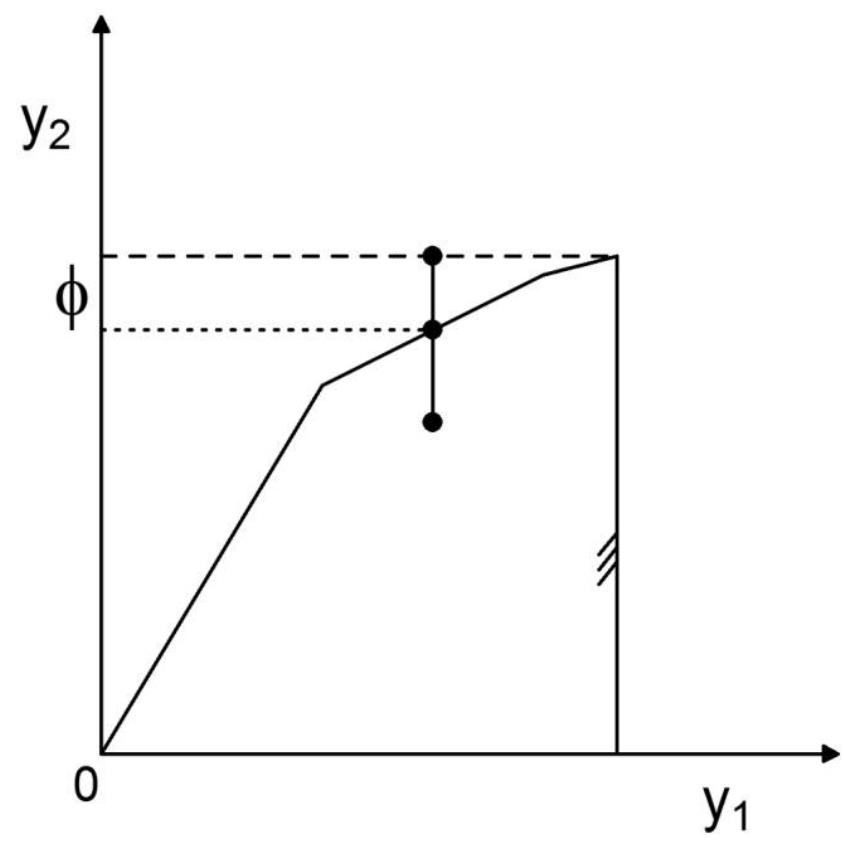

Figure 3. Separation between Strong and Weak Output Disposal Efficient Frontiers

Note: Segmented line illustrates directional distance function approach, expanding interior production point in the $\mathrm{y}_{2}$ direction toward weak (solid line) and strong (dashed) output disposal efficient frontiers. Frontier separation $(\phi)$ corresponds to additional $\mathrm{y}_{2}$ producible under efficient production and strong $\mathrm{y}_{1}$ disposal.

Bank following the 2010 catch share implementation, where medians across all observations in each region before and after the policy change were compared. This nonparametric test evaluates the null hypothesis that the medians of populations from which two samples are drawn are identical. It is robust to outliers and does not assume equal variances across samples (Siegel and Castellan 1988). The test was performed by calculating the overall median for the combined sample (all $\phi$ in a particular region) and then applying Fisher's exact test on a contingency table specifying the number of observations before and after the policy change that were above and below the overall median value.

Changes in fishing selectivity may arise due to changes in the environment or technology, as well as changes in fishing behavior. Additionally, changes in the temporal and spatial distribution of observer coverage could affect perceived changes in fishing selectivity. To control for several potentially confounding factors-including spatially and temporally heterogeneous observer coverage - we used fixed effects quantile regressions. Quantile regressions formulate the conditional quantile as a function of independent variables in a manner similar to how linear regressions specify the conditional mean to depend on a set of independent covariates. In this analysis, we specified the conditional median of $\phi$ to be a linear function of statistical area, month, and individual vessel fixed effects; variable input factors; spawning stock biomass; and a catch share indicator that equaled one for all tows taken by catch share vessels following the 2010 management change and zero otherwise. Fixed effects were used to control for common shocks arising due to broad environmental conditions, differences in individual vessels' fishing selectivity, and potential shifts in observer coverage. Including variable factors of production and spawning stock biomass con- 
trolled for changes in production inputs that might influence selectivity but were exogenous to the policy. ${ }^{12,13}$ Four quantile regressions were run — one for each of the two output distance measures (expanding haddock and expanding all non-cod outputs) in the Gulf of Maine and Georges Bank. Parameter standard errors were constructed using a clustered bootstrap, clustering by areamonth-FY strata. Pseudo $\mathrm{R}^{2}$ values were calculated after each regression following Koenker and Machado (1999). The estimated coefficient on our policy indicator was interpreted as the change in median frontier difference associated with the implementation of catch share management, possibly arising due to fine-scale changes in spatiotemporal fishing decisions (i.e., behavioral changes within a statistical area and/or month).

In calculating (6), linear programming routines (7) and (8) considered all 40,692 observed tows in the Gulf of Maine and Georges Bank by FY and area-month strata. Subsequent analyses of medians, including quantile regressions, considered only observations by those vessels that ultimately transitioned to catch shares (FYs 2007-2009) or were fishing under catch shares (FYs 2010-2014). This removed approximately $20 \%$ of observed tows, largely occurring prior to the 2010 implementation by vessels that subsequently left the fishery. ${ }^{14}$ Due to the potential influence of outliers and extreme data points, once analyses were complete, all models were re-run, excluding observed tows whose total catch fell in the upper or lower deciles of all catch observations in the Gulf of Maine and Georges Bank. All computations were performed in the statistical software $\mathrm{R}$ (R Core Team 2017). The package lpSolveAPI (lp_solve and Konis 2016) was used in constructing and solving linear programming problems, while the package quantreg (Koenker 2017) was used for quantile regressions.

\section{RESULTS}

Production frontiers were constructed for 540 of 1,248 strata ( 43\%), split almost equally between the Gulf of Maine and Georges Bank (online-only appendix A; tables A1, A2). Each strata had an average of 75 tows that yielded solutions to linear programming problems (7) and (8). There was considerable variation across production frontiers constructed for tows in Georges Bank during the first three FYs, as these strata tended to have more observations. Efficiency scores, calculated using directional distances to the weak output disposal efficient frontier and ranging between 0 and 1 , averaged 0.36 when expanding haddock and 0.83 when expanding all non-cod outputs (online-only tables A3, A4). As our directional measures expanded additively, observations of zero catch yielded efficiency scores of zero. Thus, when expanding only one output (haddock), $\sim 25 \%$ of observations defined the efficient frontier, on average; though when expanding multiple outputs (all non-cod outputs), $\sim 50 \%$ of observations were considered efficient. Mean efficiency scores for tows in Georges Bank increased following the implementation of catch shares, while efficiency scores for tows in the Gulf of Maine exhibited no obvious temporal trend.

Calculating (6) using a specification of the directional vector that expanded only haddock produced values of $\phi$ that were frequently greater than zero (figure 4, online-only table A5), implying weak haddock selectivity; i.e., limited haddock targeting ability. Considering all observations

\footnotetext{
12. If haul duration or the number of crew were margins by which vessels actively influenced selectivity under catch share management, including them in quantile regressions could yield a conservative estimate of the policy indicator.

13. Quantile regressions considering frontier separation when expanding haddock (haddock targeting) included haddock biomass, while regressions considering frontier separation when expanding all non-cod outputs (cod avoidance) included cod biomass.

14. Observations from vessels that did not transition to catch shares were included when constructing production frontiers given their similar technology and production possibilities.
} 
(a)

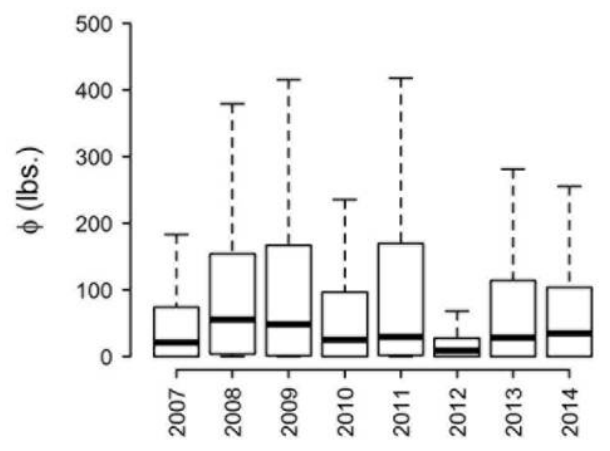

(c)

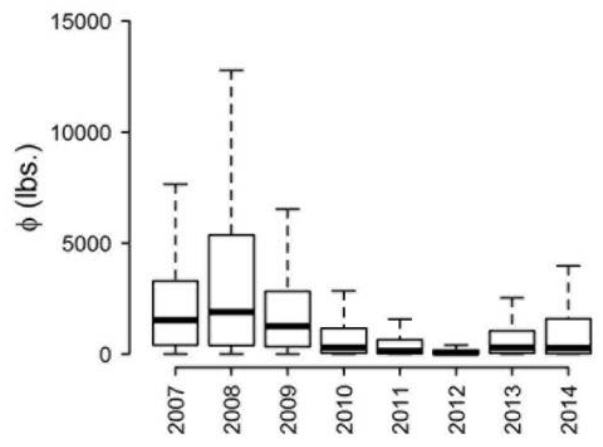

(b)

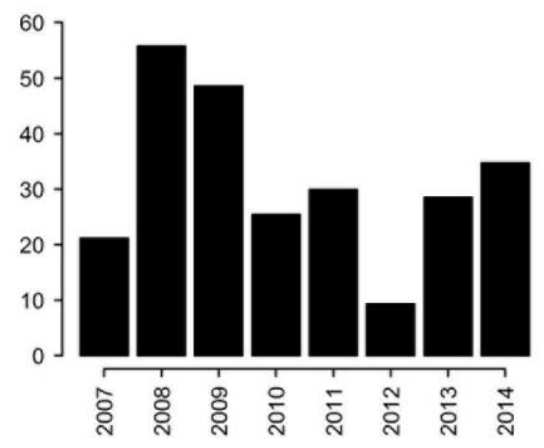

(d)

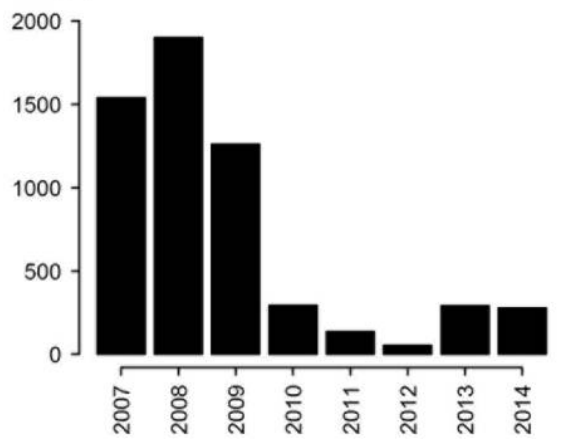

Figure 4. Boxplots (a, c) and Median Values (b, d) of $\phi$ by FY using a Directional Vector to Expand Haddock Only

Note: $\phi$ values correspond to the increase in haddock catch per tow under efficient production and strong non-haddock disposal. Panels depict measures calculated from observed tows in the Gulf of Maine (a, b) and Georges Bank (c, d) by catch share bottom trawlers. For boxplots: box covers the interquartile range with a heavy bar at the median and whiskers extending to extreme data points that are no more than 1.5 times the interquartile range. All FY median values were statistically different from zero based on 10,000 bootstrapped samples.

from vessels that ultimately transitioned to catch shares (FYs 2007-2009) or were fishing under catch shares (FYs 2010-2014), 75 and 89\% of tows exhibited evidence of weak haddock targeting $(\phi>0)$ in the Gulf of Maine and Georges Bank, respectively. Measures were found to differ substantially between fishing regions, with potential haddock increases in the Gulf of Maine generally much smaller than those found for tows in Georges Bank. For example, in the Gulf of Maine, values of $\phi$ were frequently less than $50 \mathrm{lbs}$. (median $28.85 \mathrm{lbs}$., online-only table A5) and represented a potential $10 \%$ increase in haddock composition, on average, from roughly 2 to $12 \%$ of catch. ${ }^{15}$ Conversely, in Georges Bank, frontier separation measures were often several hundred to more than 1,000 lbs. (median 938 lbs., online-only table A5), and suggested haddock compositions might have increased by $35 \%$, from 8 to $43 \%$ of catch per tow, given efficient production and strong haddock selectivity.

15. Increases in percent composition were calculated by adding $\phi$ to catch observations. 
Defining the directional vector to expand all non-cod outputs yielded results qualitatively similar to those found when expanding haddock only (figure 5, online-only table A6). Evidence of weak cod avoidance was seen in 75 and 85\% of tows taken in the Gulf of Maine and Georges Bank, respectively. Larger values were again observed in Georges Bank, though differences between the fishing regions were less pronounced. Median frontier separation for tows in the Gulf on Maine was 16.43 lbs., while in Georges Bank this value was 50.79 lbs. (online-only table A6). Overall, values tended to be much lower than those found when measuring frontier separation by expanding haddock only. This finding is logical, as we would expect larger single-species output increases given perfect targeting of that species when compared to output increases for each of several species given perfect avoidance of a single, jointly caught species.

Based on our bootstrapping method, in both the Gulf of Maine and Georges Bank, median $\phi$ values were found to be significantly greater than zero in all FYs and using both specifications of the directional vector. This finding indicates weak fishing selectivity is pervasive within the Northeast multispecies bottom trawl fishery. Interestingly, statistical areas at northern, eastern, and southern geographic extremes were found to have stronger fishing selectivity. In statistical ar-

(a)

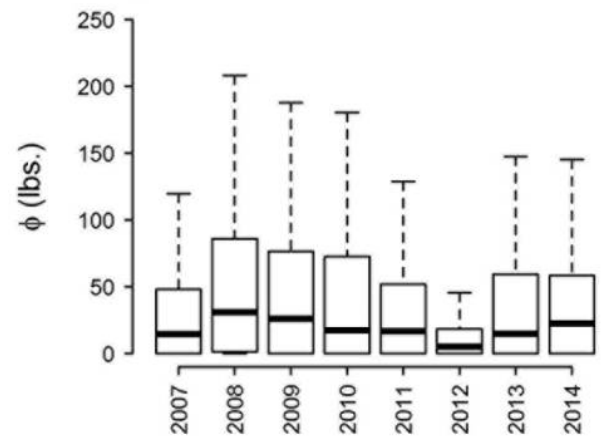

(c)

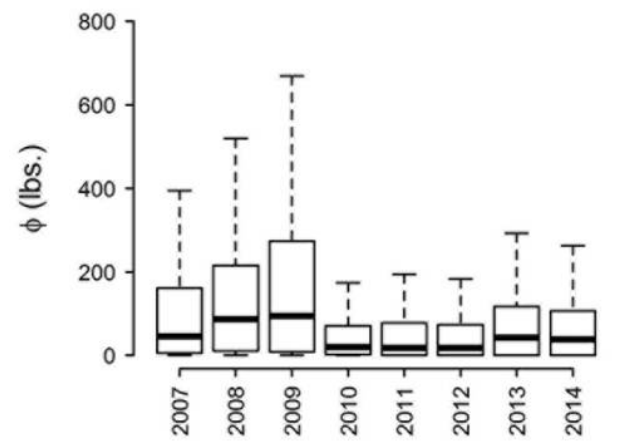

(b)

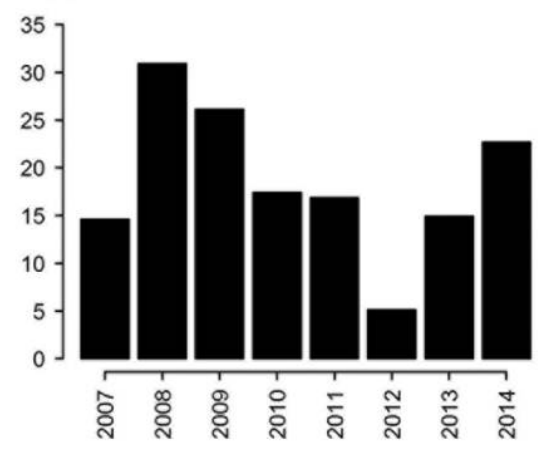

(d)

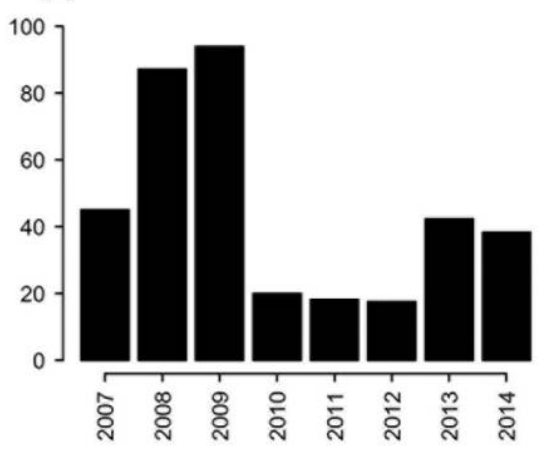

Figure 5. Boxplots ( $a, c)$ and Median Values (b, d) of $\phi$ by FY using a Directional Vector to expand Haddock, Roundfish, Flatfish, and the Aggregate of Species Managed Outside the Multispecies FMP

Note: $\phi$ values correspond to the increase in non-cod catch per output per tow under efficient production and strong cod disposal. Panels depict measures calculated from observed tows in the Gulf of Maine (a, b) and Georges Bank (c, d) by catch share bottom trawlers. For boxplots: box covers the interquartile range with a heavy bar at the median and whiskers extending to extreme data points that are no more than 1.5 times the interquartile range. All FY median values were statistically different from zero based on 10,000 bootstrapped samples. 
eas 464,512 , and 526 , more than half of the tow-level selectivity measures were equal to zero, suggesting production in these areas was characterized by strong output disposal among the outputs considered in our analysis.

Median values of $\phi$ differed significantly before and after the 2010 introduction of catch shares in both fishing regions and using both specifications of the directional vector (table 3 ). In all instances, medians were seen to decrease, indicating a reduction in separation between strong and weak output disposal efficient production frontiers - or an increase in observed fishing selectivity. Median decreases were far more substantial in Georges Bank where, for example, the median value of $\phi$ computed for vessels prior to fishing under catch shares was $1,506 \mathrm{lbs}$., with a subsequent reduction to $182 \mathrm{lbs}$., a drop of $88 \%$. In all cases, medians declined by $40 \%$ or more.

Quantile regressions indicated that catch shares were associated with significant reductions in frontier separation in Georges Bank, but not the Gulf of Maine (online-only tables A7-A10). After controlling for several factors that might affect observed differences in fishing selectivity, median $\phi$ values were estimated to have decreased by 953 and 61 lbs. per tow, respectively, in Georges Bank when expanding outputs in haddock and non-cod multi-output directions (table 3). These decreases represent reductions in frontier separation of 63 and $84 \%$. In the Gulf of Maine, catch shares were not correlated with the observed increases in fishing selectivity after accounting for the potential influence of confounding factors. Quantile regression estimates in Georges Bank differed from observed median changes due to an increased number of observed tows by slightly more selective vessels fishing in statistical areas where selectivity tended to be slightly worse (areas 521 and 522). These potentially confounding processes (where and on what vessel observations occurred) led to exaggerated median changes in haddock targeting and understated median changes in cod avoidance. In the Gulf on Maine, where quantile regressions suggest no significant policy effects, changes in observer coverage appear to be responsible for shifts in median $\phi$ values. Annual biomass estimates were not found to substantially influence fishing selectivity; perhaps due to differences in scale (catch per tow being affected by local abundance levels). Variable input factors (haul duration and crew size) were marginally significant in a few instances with increases tending to increase $\phi$ values, or decrease selectivity. All regressions had low pseudo $\mathrm{R}^{2}$ s, indicating large amounts of variation in selectivity measures remained unexplained (online-only tables A7-A10).

Removing observations in which total catch fell within the upper and lower deciles, and then subsequently re-running all models and analyses, yielded results which were qualitatively similar to those presented based on the full set of data (see online-only appendix B). In particular, sig-

Table 3. Median Values of $\phi$ Before (FYs 2007-2009) and After (FYs 2010-2014) Introduction of Catch Share Management

\begin{tabular}{lcccc}
\hline Area (Output Expansion) & FYs 2007-2009 & FYs 2010-2014 & $\Delta \phi$ & QR $\beta_{c s}$ \\
\hline Gulf of Maine (haddock) & 40.17 & 23.24 & $-16.93^{* * *}$ & -0.67 \\
Gulf of Maine (non-cod) & 22.68 & 13.69 & $-8.99^{* * *}$ & -3.92 \\
Georges Bank (haddock) & $1,505.81$ & 182.03 & $-1,323.78^{* * *}$ & $-953.26^{* * *}$ \\
Georges Bank (non-cod) & 72.97 & 24.49 & $-48.48^{* * *}$ & $-61.46^{* * *}$ \\
\hline
\end{tabular}

Note: Direction of output expansion is specified in parentheses. Mood's median tests were used to determine if median values differed significantly, with a null hypothesis of equal medians. Catch share policy indicator parameter estimates from quantile regressions are also presented. ${ }^{*},{ }^{* *}$, and ${ }^{* *}$ denote statistical significance at the 10,5 , and $1 \%$ levels, respectively. 
nificant weak selectivity was found in all FYs in both fishing regions. Furthermore, quantile regressions revealed significant reductions in frontier separation in Georges Bank, but not the Gulf of Maine, following the introduction of catch share management. The absolute magnitude of change in median values was less than that calculated when using the full set of data, as frontiers no longer included observations of extremely large or extremely small tows. Shifts in median values were proportionally similar, however. In Georges Bank, decreases in frontier separation following the introduction of catch shares represented reductions of 62 and $67 \%$ when outputs were expanded in haddock and non-cod, multi-output directions, respectively (online-only table B1). This analysis suggests that catch outliers and extreme data points did not substantially affect the prevalence of weak output disposal in multispecies production sets, differences observed between the Gulf of Maine and Georges Bank, or changes in fishing selectivity observed following the 2010 introduction of rights-based output controls.

\section{DISCUSSION}

Fishing selectivity was measured using directional distance functions, largely following methods first applied to evaluate opportunity costs of pollution regulation (Färe, Grosskopf, and Pasurka 2007) and later extended to multispecies fisheries (Scheld and Anderson 2016). The difference between efficient production frontiers satisfying conditions of strong and weak output disposal captures the level of output forgone as a result of weak output disposability (weak fishing selectivity). This measure was found to be influenced by spatiotemporal and individual factors, as well as policy context.

In both the Gulf of Maine and Georges Bank, during all FYs and using both specifications of the directional vector, empirical production frontiers were largely found to be characterized by weak output disposability. Weak output disposal is a commonly assumed technological condition used in theoretical descriptions of multispecies production technologies, as it allows for positive marginal rates of product transformation between species and proportionate output reductions, such as might occur by taking fewer (or shorter) tows in an area or reducing vessel capacity (Turner 1997; Singh and Weninger 2009; Reimer, Abbott, and Wilen 2017). Our findings agree with these standard descriptions of multispecies fishing technologies and, additionally, support prior empirical investigations of the Northeast groundfish fleet. For example, Squires (1987) found multispecies production by Northeast groundfish trawlers to be joint and non-separable, and Scheld and Anderson (2016) observed significant evidence of weak output disposability in daily groundfish landings.

The magnitude of weak selectivity was seen to differ across fishing regions. Spatial heterogeneity in technical interaction is expected, given differing distributions of target species (Reimer, Abbott, and Wilen 2017), as well as spatial heterogeneity in the groundfish fleet, with vessels fishing Georges Bank tending to be slightly larger, on average. When expanding haddock in Georges Bank, median measures of frontier separation were 30 times larger than those found for the Gulf of Maine. Though tows in Georges Bank were somewhat larger in total and contained greater amounts of haddock, the dramatic difference in frontier separation values between the two regions suggests considerable differences in technical interaction between species, with much more haddock potentially forgone in Georges Bank as a result of weak fishing selectivity. Regional differences were less substantial when directional distance functions expanded all non-cod outputs, however. This asymmetry appears to indicate that, while the potential for improved haddock targeting might have been much greater in Georges Bank, the ability and potential to avoid cod was more homog- 
enous across regions - a finding in agreement with relative stock conditions - as Georges Bank haddock is estimated to be an order of magnitude greater than both cod stocks and Gulf of Maine haddock (NEFSC 2015).

Following the 2010 implementation of catch shares initiated through A16 to the Northeast multispecies FMP, significant decreases in the difference between strong and weak output disposal efficient production frontiers were observed. These decreases suggest improvements in fishing selectivity and reduced costs associated with imperfect compositional control. More specifically, subsequent to the introduction of rights-based output controls, efficient production frontiers - still largely characterized by weak selectivity — exhibited reduced tradeoffs in joint production of haddock, cod, and other groundfish. In Georges Bank, quantile regressions indicated that, subsequent to A16, more haddock could be produced for a given level of non-haddock (improved haddock targeting) and that more non-cod could be produced for a given level of cod (improved cod avoidance). Regressions included spatial and temporal fixed effects and variable input factors, which could yield conservative estimates of selectivity changes if behavioral response occurred at large spatial or temporal scales (statistical areas or months) or through changes in levels of variable inputs. Interestingly, changes in median selectivity values for tows in the Gulf of Maine following A16 were not statistically significant after controlling for spatiotemporal and individual factors. This differential policy effect observed between the two regions may be due to the large annual allocations of Georges Bank haddock providing strong incentives to target the stock. ${ }^{16}$

While a causal relationship between the policy change and revealed production possibilities was not identified in this research, our findings suggest a significant correlation and agree with investigations of other fisheries that report more flexible production and improved species targeting following the introduction of rights-based output controls (Branch and Hilborn 2008; Abbott, Haynie, and Reimer 2015). However, policy decisions do not occur in a vacuum, and given ex-ante knowledge of a catch share implementation, we might expect strategic anticipatory behavior by vessels (Brandt 2007). Sector allocations were based on member landings during FYs 1996-2006 for most stocks and 1996-2001 for Georges Bank cod. This substantial gap between activities influencing allocation and subsequent policy implementation may have reduced the incentive for, or ability of, vessels to strategically react. The large-scale transition of allowable harvest to tradeable sector quota ( $>98 \%)$ suggests selection effects were perhaps minimal in this instance, as most vessels harvesting multispecies groundfish joined sectors. Unfortunately, a reasonable control group was not available for comparison, as those vessels that did not join sectors and continued to fish under effort controls were also limited by a common-pool quota.

The data used in this analysis was obtained from observed trips taken by the Northeast multispecies groundfish fleet. As not all trips carried observers, median selectivity values constructed for tows taken before and after policy implementation were influenced by where, when, and with whom tows were observed. Quantile regressions enabled control of individual vessel fixed effects and shifts in observer coverage; however, it is possible that the selectivity improvements seen in Georges Bank resulted from factors outside those considered and unrelated to the policy change. Relying on data from fishery observers could limit extrapolation of our results to unobserved trips if vessels changed their behavior due to the presence of observers. We do not believe this limits

16. In addition to quota constraints, targeting and avoidance may be incentivized by relative prices and costs associated with fishing for each species. These factors were not thought to influence observed changes discussed here, as they remained relatively constant throughout the time period considered. 
interpretability of our results within, at least, the narrowly defined context of observed trips before and after a policy change. Further exploration of "observer effects" in the Northeast multispecies groundfish fleet would aid in determining whether observations used here are representative.

Shifts in our frontier selectivity measure arose due to changes in catch ratios among species for observations defining the efficient frontier. ${ }^{17}$ Following the policy change, tows in Georges Bank caught more haddock, less cod, and were less variable. Median haddock catch increased by 8 lbs./ tow, while median cod catch decreased by $11.2 \mathrm{lbs}$./tow — changes which agree with our frontier estimates, indicating improved haddock targeting and cod avoidance. Additionally, tows saw a $21 \%$ reduction in total catch variability and improved efficiency. Reductions in catch variability, perhaps by avoiding areas or times known to have variable species compositions and densities, are strategies observed elsewhere and have been associated with improved selectivity subsequent to the introduction of rights-based output controls (Branch and Hilborn 2008; Abbott, Haynie, and Reimer 2015). Atlantic cod are known to aggregate into dense concentrations in certain areas and at particular times for spawning and forage (Zemeckis, Dean, and Cadrin 2014; Richardson, Palmer, and Smith 2014); avoiding these areas could reduce the likelihood of rare large tows containing significant levels of cod.

Changes in revealed multispecies production possibilities arise due to changes in spatiotemporal decision making by fishers (Reimer, Abbott, and Wilen 2017; Reimer, Abbott, and Haynie 2017). In Georges Bank, results from quantile regressions suggest that fine-scale spatiotemporal decisions may ultimately influence catch composition and are perhaps difficult to resolve with the level of analysis conducted here. For example, our analysis does not consider changes in tow direction or time of day, which have been found to influence fishing selectivity in other research (Abbott, Haynie, and Reimer 2015). Investigation of fishing behavior at a finer spatial resolution could help determine whether such strategies were used in achieving improvements in selectivity found in the analysis described here.

We defined fishing selectivity as the difference between strong and weak output disposal efficient production frontiers and evaluated empirical measures across fishing areas and years. This construction controls for production inefficiencies that may confound other, non-frontier descriptions of technology. Frontier measures are influenced by outliers, extreme data points, and rare events, and may be affected by decisions regarding the level of analysis conducted (e.g., the degree of spatial or temporal aggregation). We chose to construct production frontiers by statistical area and month strata to control for unobserved environmental factors and also position the analysis within a setting relevant to management. Stratifications that explicitly consider environmental factors (e.g., depth) could yield production frontiers that are more contextually homogenous, but less spatially contiguous or management relevant. Median selectivity values constructed across multiple production strata are influenced by production possibilities within each strata, as well as the distribution of observations across and within individual strata. Once calculated, additional analyses (e.g., quantile regressions) can be used to control and explore a variety of factors thought to affect average selectivity measures.

Applications of data envelopment analysis and directional distance functions in multispecies fisheries have often focused on estimation and evaluation of technical efficiency (see e.g., Dupont et al. 2002; Färe, Kirkley, and Walden 2006, 2011). Utilizing this methodological framework, we

17. Changes in average values or other statistics derived from selectivity measures also depend on the distribution of observations within a frontier. 
explored a measure of fishing selectivity in the context of a large-scale management change thought to promote targeting and avoidance of individual stocks. The measure is non-marginal and is perhaps most useful in broadly characterizing multispecies production technologies and calculating gross inter-species production tradeoffs, possibly in relation to policy, environmental, or behavioral factors. For example, the measure could be used to identify technically feasible multispecies allocations or assess forgone revenues associated with constraining multispecies quotas. Use of this measure for ex-ante prediction would need to appropriately consider how management and other exogenous factors influence revealed production possibilities (Reimer, Abbott, and Wilen 2017; Reimer, Abbott, and Haynie 2017). Modeling multi-output production often requires normalizing outputs, typically by a primary output or target; however, directional distance functions allow output expansion in multiple directions, which may be useful when multiple species are thought to be targeted or avoided.

\section{CONCLUSIONS}

Improved fishing selectivity was a stated goal of A16 to the Northeast multispecies FMP that implemented catch share management for the groundfish complex (NEFMC 2009). This research suggests that revealed production possibilities for observed bottom trawls by the groundfish fleet exhibited evidence of improved fishing selectivity in Georges Bank subsequent to the management change. Nevertheless, production frontiers were largely characterized by weak output disposability throughout the time period considered. From FY 2010, when A16 was introduced, through FY 2016, quota utilization rates for cod stocks have typically fluctuated between 70 and $95 \%$. More often than not, however, less than $20 \%$ of the Georges Bank haddock allocation has been landed. Using a below market price of $\$ 1 / 1 b$., this implies that more than $\$ 50$ million in haddock allocation remains unfished each season. Despite the observed improvements in fishing selectivity, limited utilization of the Georges Bank haddock allocation could result if quota for cod and other groundfish species are limiting haddock production.

\section{REFERENCES}

Abbott, J. K., A. C. Haynie, and M. N. Reimer. 2015. "Hidden Flexibility: Institutions, Incentives, and the Margins of Selectivity in Fishing." Land Economics 91(1):169-95.

Branch, T. A., and R. Hilborn. 2008. "Matching Catches to Quotas in a Multispecies Trawl Fishery: Targeting and Avoidance Behavior under Individual Transferable Quotas." Canadian Journal of Fisheries and Aquatic Sciences 65(7):1435-46.

Brandt, S., 2007. "Evaluating Tradable Property Rights for Natural Resources: The Role of Strategic Entry and Exit." Lournal of Economic Behavior \& Organization 63(1):158-76.

Chambers, R. G., Y. Chung, and R. Färe. 1996. "Benefit and Distance Functions.” Journal of Economic Theory 70(2):407-19.

Charnes, A., W. W. Cooper, and E. Rhodes. 1978. "Measuring the Efficiency of Decision Making Units." European Journal of Operational Research 2(6):429-44.

Chung, Y. H., R. Färe, and S. Grosskopf. 1997. "Productivity and Undesirable Outputs: A Directional Distance Function Approach.” Lournal of Environmental Management 51(3):229-40.

Copes, P. 1986. “A Critical Review of the Individual Quota as a Device in Fisheries Management." Land Economics 62(3):278-91.

Dupont, D. P., R. Q. Grafton, J. Kirkley, and D. Squires. 2002. "Capacity Utilization Measures and Excess Capacity in Multi-Product Privatized Fisheries." Resource and Energy Economics 24(3):193-210. 
Färe, R., and S. Grosskopf. 2004. "Modeling Undesirable Factors in Efficiency Evaluation: Comment." European Journal of Operational Research 157(1):242-45.

Färe, R., S. Grosskopf, and C. A. Knox Lovell. 1994. Production Frontiers. Cambridge, UK: Cambridge University Press.

Färe, R., S. Grosskopf, and C. A. Pasurka. 2007. "Environmental Production Functions and Environmental Directional Distance Functions." Energy 32(7):1055-66.

Färe, R., J. E. Kirkley, and J. B. Walden. 2006. "Adjusting Technical Efficiency to Reflect Discarding: The Case of the U.S. Georges Bank Multi-Species Otter Trawl Fishery." Fisheries Research 78(2006):25765.

_. 2011. "Measuring Fishing Capacity When Some Outputs are Undesirable." Eastern Economic Journal 37(4):553-70.

Farrell, M. J. 1957. "The Measurement of Productive Efficiency." Journal of the Royal Statistical Society. Series A (General) 120(3):253-90.

Grafton, R. Q., R. Arnason, T. Bjørndal, D. Campbell, H. F. Campbell, C. W. Clark, R. Connor, D. P. Dupont, R. Hannesson, and R. Hilborn. 2006. "Incentive-Based Approaches to Sustainable Fisheries." Canadian Lournal of Fisheries and Aquatic Sciences 63(3):699-710.

Koenker, R. 2017. “Quantreg: Quantile Regression.” R package version 5.33. https://CRAN.R-project.org $/$ package $=$ quantreg.

Koenker, R., and J. A. Machado. 1999. "Goodness of Fit and Related Inference Processes for Quantile Regression." Lournal of the American Statistical Association 94(448):1296-310.

Kuriyama, P. T., T. A. Branch, M. A. Bellman, and K. Rutherford. 2016. "Catch Shares Have Not Led to CatchQuota Balancing in Two North American Multispecies Trawl Fisheries." Marine Policy 71(2016):60-70.

Lee, M-Y. A., and E. M. Thunberg. 2013. "An Inverse Demand System for New England Groundfish: Welfare Analysis of the Transition to Catch Share Management." American Journal of Agricultural Economics 95(5):1178-95.

lp_solve, and K. Konis. 2016. "IpSolveAPI: R Interface to 'lp_solve' Version 5.5.2.0." R package version 5.5.2.0-17. https://CRAN.R-project.org/package $=$ lpSolveAPI.

Murphy, T., A. Kitts, D. Records, C. Demarest, M. McPherson, J. Walden, D. Caless, E. Bing-Sawyer, S. Steinbeck, and J. Olson. 2011. "Final Report on the Performance of the Northeast Multispecies (Groundfish) Fishery (May 2011-April 2012).” US Department of Commerce, Northeast Fisheries Science Center Reference Document, 12-30.

NEFMC (New England Fishery Management Council). 2009. "Amendment 16 to the Northeast Multispecies Fishery Management Plan.” http://federalregister.gov/r/0648-AW72.

NEFMC, MAFMC (Mid-Atlantic Fishery Management Council), and NOAA (National Marine Fisheries Service). 2007. "Northeast Region Standardized Bycatch Reporting Methodology: An Omnibus Amendment to the Fishery Management Plans of the New England and Mid-Atlantic Fishery Management Councils." June, Woods Hole, MA.

NEFSC (Northeast Fisheries Science Center). 2015. "Operational Assessment of 20 Northeast Groundfish Stocks, Updated Through 2014." US Department of Commerce, Northeast Fisheries Science Center Reference Document 15-24. Woods Hole, MA.

Palmer, M. C., P. Hersey, H. Marotta, G. Shield, S. B. Cierpich. 2013. "The Design, Implementation and Performance of an Observer Pre-Trip Notification System (PTNS) for the Northeast United States Groundfish Fishery." US Department of Commerce, Northeast Fisheries Science Center Reference Document 13-21. Woods Hole, MA

Pascoe, S., P. Koundouri, and T. Bjørndal. 2007. "Estimating Targeting Ability in Multi-Species Fisheries: A Primal Multi-Output Distance Function Approach." Land Economics 83(3):382-97.

Pascoe, S., A. E. Punt, and C. M. Dichmont. 2010. "Targeting Ability and Output Controls in Australia's Multi-Species Northern Prawn Fishery." European Review of Agricultural Economics 37(3):313-34. 
R Core Team. 2017. "R: A Language and Environment for Statistical Computing.” R Foundation for Statistical Computing, Vienna, Austria. https://www.R-project.org/.

Reimer, M. N., J. K. Abbott, and A. C. Haynie. 2017. "Empirical Models of Fisheries Production: Conflating Technology with Incentives?” Marine Resource Economics 32(2):169-90.

Reimer, M. N., J. K. Abbott, and J. E. Wilen. 2017. "Fisheries Production: Management Institutions, Spatial Choice, and the Quest for Policy Invariance." Marine Resource Economics 32(2):143-68.

Richardson, D. E., M. C. Palmer, and B. E. Smith. 2014. "The Influence of Forage Fish Abundance on the Aggregation of Gulf of Maine Atlantic Cod (Gadus morhua) and their Catchability in the Fishery." Canadian Journal of Fisheries and Aquatic Sciences 71(9):1349-62.

Sanchirico, J. N., D. Holland, K. Quigley, and M. Fina. 2006. "Catch-Quota Balancing in Multispecies Individual Fishing Quotas.” Marine Policy 30(6):767-85.

Scheld, A. M., and C. M. Anderson. 2016. "Selective Fishing and Shifting Production in Multispecies Fisheries." Canadian Journal of Fisheries and Aquatic Sciences 74(3):388-95.

Shephard, R. W. 1970. Theory of Cost and Production Functions, ed., David Gale and Harold W. Kuhn. Princeton, NJ: Princeton University Press.

Siegel, S., and N. J. Castellan. 1988. Nonparametric Statistics for the Behavioral Sciences, 2nd ed. New York, NY: McGraw-Hill.

Singh, R., and Q. Weninger. 2009. "Bioeconomies of Scope and the Discard Problem in Multiple-Species Fisheries." Lournal of Environmental Economics and Management 58(1):72-92.

Squires, D. 1987. "Public Regulation and the Structure of Production in Multiproduct Industries: An Application to the New England Otter Trawl Industry." The Rand Journal of Economics 18(2):232-47.

Squires, D., H. Campbell, S. Cunningham, C. Dewees, R. Q. Grafton, S. F. Herrick, Jr., J. Kirkley, S. Pascoe, K. Salvanes, and B. Shallard. 1998. "Individual Transferable Quotas in Multispecies Fisheries.” Marine Policy 22(2):135-59.

Squires, D., and J. Kirkley. 1991. "Production Quota in Multiproduct Pacific Fisheries." Lournal of Environmental Economics and Management 21(2):109-26.

Turner, M. A. 1997. “Quota-Induced Discarding in Heterogeneous Fisheries.” Lournal of Environmental Economics and Management 33(2):186-95.

Zemeckis, D. R., M. J. Dean, and S. X. Cadrin. 2014. "Spawning Dynamics and Associated Management Implications for Atlantic Cod." North American Journal of Fisheries Management 34(2):424-42. 